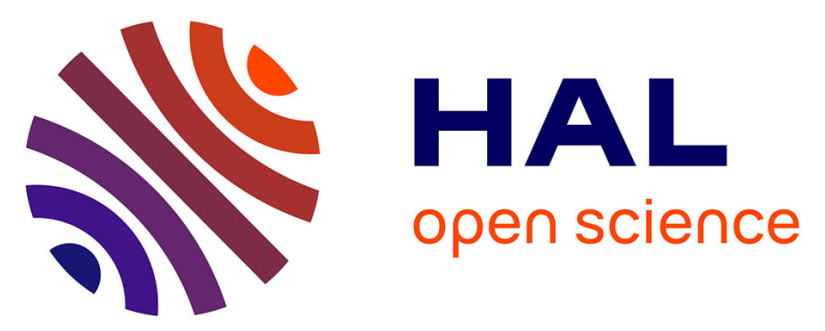

\title{
On a failure criterion for thermomechanical multiaxial low cycle fatigue and its industrial application
}

\author{
E. Charkaluk, A. Constantinescu, A. Bignnonet, K. Dang Van
}

\section{To cite this version:}

E. Charkaluk, A. Constantinescu, A. Bignnonet, K. Dang Van. On a failure criterion for thermomechanical multiaxial low cycle fatigue and its industrial application. Fourth International Conference on Low Cycle Fatigure and Elasto-Plastic Behavior of Materials, Sep 1998, Garmisch-Partenkirchen, Germany. pp.815-820. hal-00116524

\section{HAL Id: hal-00116524 https://hal.science/hal-00116524}

Submitted on 26 Aug 2019

HAL is a multi-disciplinary open access archive for the deposit and dissemination of scientific research documents, whether they are published or not. The documents may come from teaching and research institutions in France or abroad, or from public or private research centers.
L'archive ouverte pluridisciplinaire HAL, est destinée au dépôt et à la diffusion de documents scientifiques de niveau recherche, publiés ou non, émanant des établissements d'enseignement et de recherche français ou étrangers, des laboratoires publics ou privés. 


\title{
ON A FAILURE CRITERION FOR THERMOMECHANICAL MULTIAXIAL LOW CYCLE FATIGUE AND ITS INDUSTRIAL APPLICATION
}

\author{
E. CHARKALUK***, A. CONSTANTINESCU**, A. BIGNONNET*, K. DANG VAN** \\ *P.S.A. Peugeot-Citroën - Direction des Recherches et Affaires Scientifiques \\ Chemin de la Malmaison - 91570 BIEVRES - FRANCE \\ ** Laboratoire de Mécanique des Solides (CNRS URA 317) \\ Ecole Polytechnique - 91128 PALAISEAU - FRANCE
}

\begin{abstract}
The purpose of this paper is to assess the fatigue strength of complex structures submitted to low cycle thermomechanical fatigue. In a first step, the behaviour of the material in a high range of temperatures has been modelled using a simple elastoviscoplastic constitutive law. In a second step, a criterion based on the dissipated energy per cycle derived from the results of the numerical computations, allows the prediction of the fatigue strength of the structure.

Strain controlled isothermal low cycle fatigue tests were carried out on cast iron specimens for the identification of the constitutive and the fatigue laws. Temperature controlled tests on specimens and structures permitted the evaluation of the precision of the numerical computation under anisothermal loading. The lifetime prediction is showed to agree with the experiments both on specimens and structures.
\end{abstract}

\section{KEYWORDS}

Low cycle fatigue criterion, dissipated energy, constitutive law, thermal fatigue, structure computation.

\section{INTRODUCTION}

The prediction of fatigue and failure of structures submitted to thermal loading is one of the important problems in mechanical engineering. One can recognize two research directions in this field : one concentrated on the understanding and modelling of the physical phenomena underlying fatigue of materials and one concentrated on finding a robust prediction criterion to evaluate the fatigue strength of components from a structural computation. The prediction criterion should correspond to the expectation of the design engineer, i.e. to be identified from simple mechanical experiments on specimens and to be applicable on actual structures of complex geometry and complex thermomechanical loadings.

In spite of major advances in the understanding of fatigue phenomena at a local microscopic level and a large amount of experiments on specimens, robust criteria at a global macroscopic level to predict low cycle thermomechanical fatigue failure on structures are still missing. There are essentially two difficulties to attain this objective : a formulation of the material behaviour which gives access to an accurate description of the mechanical values which control the fatigue 
phenomenon in a structure and a failure criterion, derived from simple tests, which provides a reasonable estimation of the lifetime of the structure.

The constitutive law should permit computer simulations in a acceptably small computation time of elastoviscoplastic structure subjected to complex thermomechanical loadings. The fatigue criterion should be capable of explaining isothermal and anisothermal LCF failure for a large range of temperatures and for multiaxial loadings.

From a material point of view, one can identify different steps in the fatigue life time (initiation of a crack, propagation, failure of a representative elementary volume, ...). The interpretation of these steps from the point of view of applications to industrial structure permits a distinction between different situations, for example

- in the security assessment of a cracked structure, one can directly concentrate on the crack propagation rate and the critical size of the crack [1].

- in a particular design process, where no control is done after the delivery of the product to the customer, one can not accept crack growth leading to component disfunctionment before the targeted lifetime. Therefore one can consider in the design analysis the time to failure of a representative elementary volume (REV) as a failure criterion of the whole structure [2].

These considerations have suggested a certain number of assumptions in the present study:

- the material behaviour can be modeled by a simple elastoviscoplastic constitutive law, which permits the representation of the cyclic response of the structure under thermomechanical loading,

- the fatigue criterion can be based on an intrinsic quantity permitting the prediction of failure under isothermal and anisothermal multiaxial loading. The dissipated energy per cycle, seem to give good results.

This paper presents in a first section the identification of the constitutive law and in a second section the fatigue criterion and its applications to the fatigue assessment of actual structures using isothermal and anisothermal LCF experiments.

\section{EXPERIMENTS AND COMPUTATIONS}

The material studied is a spheroidal graphite cast-iron with silicium and molybden additions. Three types of test have been carried out on specimens and actual exhaust pipes of automotive engines :

- Isothermal strain controlled tests (TRV) were carried out in order to caracterize the mechanical behaviour of the material. The experiments have been done at different constant temperatures between $20^{\circ} \mathrm{C}$ and $800^{\circ} \mathrm{C}$. The applied cycle corresponds to a tensionrelaxation-recovery (TRV) test, with total strain rates applied to the specimen between $10^{-4} \mathrm{~s}^{-1}$ and $10^{-2} \mathrm{~s}^{-1}$ and maximal strain ranges between $2 \%$ and $5 \%$.

- Fully reversed isothermal low cycle fatigue tests $(\mathrm{LCF})\left(\mathrm{R}_{\varepsilon}=-1\right)$ were carried out under strain control of the material. The experiments have been done at different constant temperatures between $200^{\circ} \mathrm{C}$ and $700^{\circ} \mathrm{C}$, with a total strain rate of $10^{-3} \mathrm{~s}^{-1}$ and three different strain ranges : $\pm 0,25 \%, \pm 0,5 \%$ and $\pm 1 \%$.

- Thermal fatigue tests (TMF) were conducted on clamped specimens heaten by the Joule effect. Maximum temperatures have been varied between $40{ }^{\circ} \mathrm{C}$ and $700{ }^{\circ} \mathrm{C}$ with an heating rate of $20^{\circ} \mathrm{C} / \mathrm{s}$. The maximum temperature has been obtained in a region of approximatively $10 \mathrm{~mm}$ in the center of the specimen. The maximum temperature gradient was $30-40^{\circ} \mathrm{C} / \mathrm{mm}$. The parameters of the test are the clamp value $(183000 \mathrm{~N} / \mathrm{mm}$ and $227000 \mathrm{~N} / \mathrm{mm})$ and the dwell time at $700{ }^{\circ} \mathrm{C}(60$ seconds and 900 seconds). 
- Thermomechanical tests were carried out on engine components. Maximum temperatures have been varied between $20^{\circ} \mathrm{C}$ and $700^{\circ} \mathrm{C}$. It is important to remark that temperatures have not been distributed uniformly over the component. Some points never exceeded $200^{\circ} \mathrm{C}$. The heating rate was approximately $10^{\circ} \mathrm{C} / \mathrm{s}$.

An elastoviscoplastic constitutive law with five temperature depending parameters has been identified for each temperature on the stabilized cycle obtained with the isothermal TRV. The rheological representation is shown in Figure 1. A comparison between computation and experimentation is given in the Figure 2 and it can be observed that relaxation is reasonnably well represented with a $10 \%$ error on stresses. A difference of stress hardening was observed between compression and traction and similar behaviour for cast-iron has already been reported by Josefson et al. [3]. In the model an average of the two values of stress hardening has been used to minimize the error in tension and compression, which explains the differences between the computed and experimental curves of Figure 2.

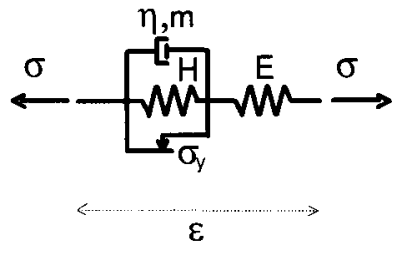

Figure $1:$ a representation of the constitutive law

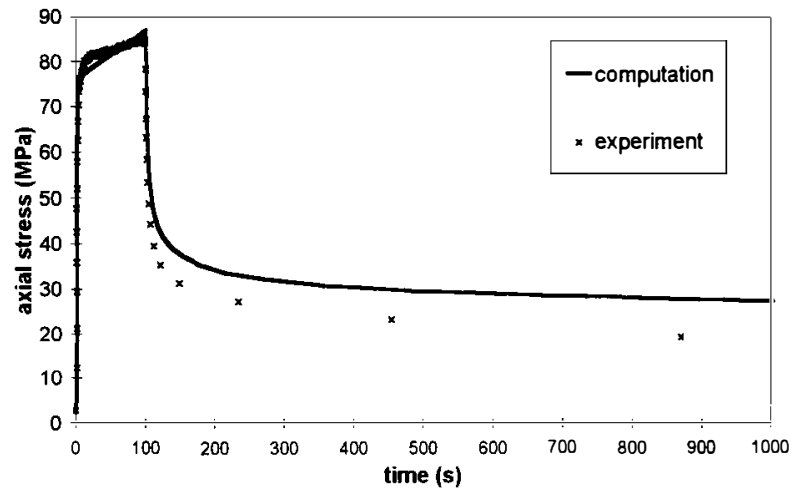

Figure 2 : strain controlled test at $700^{\circ} \mathrm{C}$

Using this elastoviscoplastic constitutive law, FEM computation using the ABAQUS code has been performed in order to simulate the anisothermal fatigue tests. A typical result of computed axial stress in the specimen versus temperature is presented in Figure 3.

The observed difference between the experimental and the computed first cycle is actually due to the constitutive parameters of the elastoviscoplastic law. However one can remark that the stabilized cycle has been evaluated both in term of residual stress at room temperature and amplitude difference between loading and unloading. The dwell temperature has been considered constant during the computation, which differs from the experiment where a $20^{\circ} \mathrm{C}$ difference due to the thermal regulation can be observed.

The irregularities at $500^{\circ} \mathrm{C}$ are due to variations of the elastoviscoplastic parameters at this temperature, corresponding to a dynamic strain ageing phenomenon. A better control of the numerical convergence of the code can be achieved and is part of the study not reported here

The anisothermal tests on components were also simulated using the same elastoviscoplastic constitutive law. A typical FEM model for an exhaust pipe containing about 20000 hexaedric volume elements is represented in Figure 4. The temperature computed distribution on the components has been checked with experimental values obtained by infrared thermography. The thermomechanical loading has been given by the temperature variation described before and stresses and strains distribution were obtained in all the structure. 


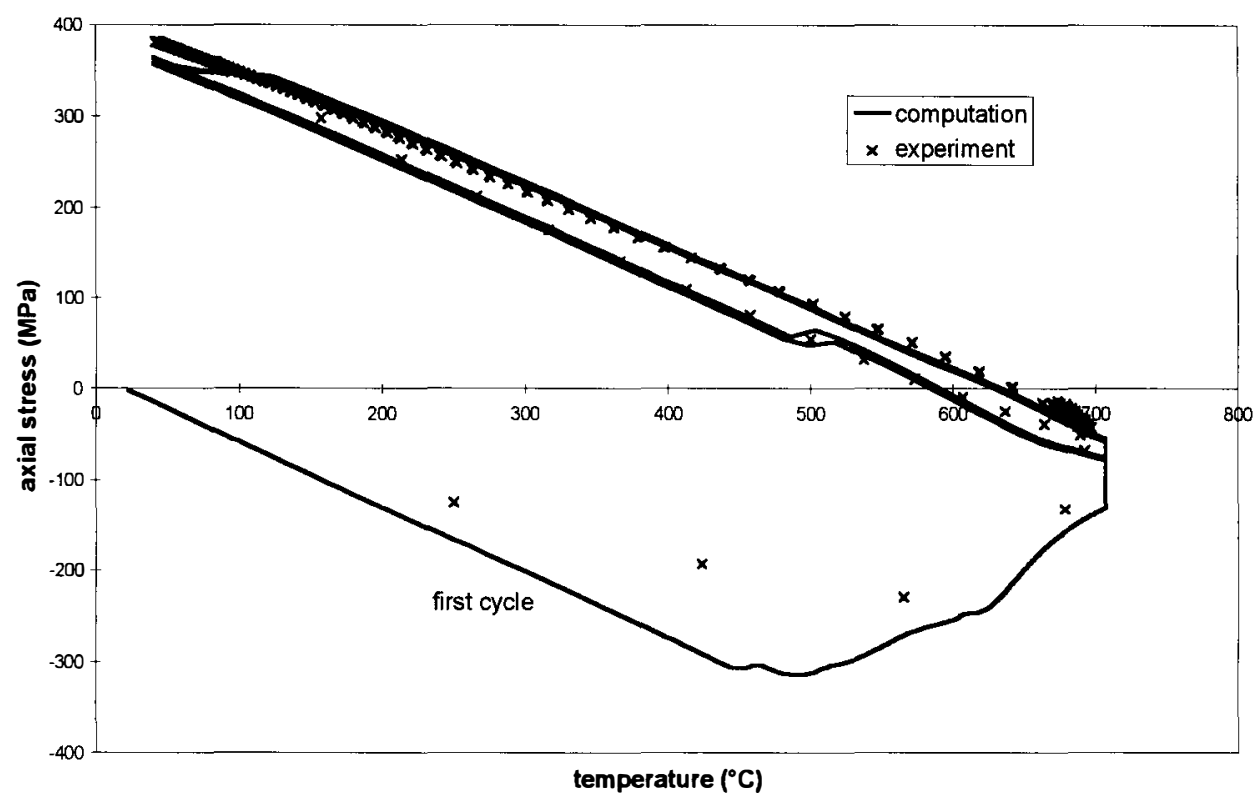

Figure 3 : comparison between the thermal fatigue test curve and the corresponding computation for a $40^{\circ} \mathrm{C}-700^{\circ} \mathrm{C}$ test with a $227000 \mathrm{~N} / \mathrm{mm}$ clamp and a $60 \mathrm{~s}$ dwell time.

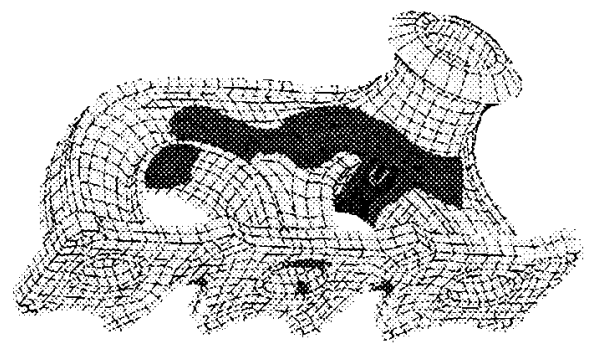

Figure 4 : FEM model of the exhaust pipe.

\section{LIFE TIME PREDICTION}

The defined objective was to determine a fatigue criterion in a multiaxial context permitting the reasonable assessment, i.e. in the standard deviation of the experimental results, of the number of cycles to failure of a representative elementary volume. The microscopic and fractographic analysis done after failure on the isothermal and anisothermal specimens showed little influence of parameters like oxydation or initial defects. This permitted a concentration on a criterion depending on mechanical state variables like stresses or strains.

A close inspection showed that the Manson-Coffin law [4, 5], the Strain-Range Partitionning (SRP) [6] or the Smith-Watson-Topper (SWT) function [7] expressed initially in an isothermal and uniaxial context are not appropriate for this problem. 
The difficulties stem essentially from the multiaxial context and the high range of attained temperatures. Classical Manson-Coffin interpretation of isothermal LCF tests shows on one hand a high difference in lifetime for the same plastic strain-range at different temperatures, and on the other hand does not give a clear generalization of a multiaxial case. This makes any interpretation of cumulated plastic strain on an anisothermal stress-strain curve hazardous and unreliable.

SWT interpretation of the anisothermal experiments are difficult as the choice of $\sigma_{\max }$ is impossible in an anisothermal case (SWT function $=\sqrt{\mathrm{E} \cdot \sigma_{\max } \cdot \Delta \varepsilon}$ ). One can remark that for cast-iron, a maximum stress for the same strain can vary from 30 to $300 \mathrm{MPa}$ depending on the temperature.

The principal criticism of the previously discussed criteria is their inapplicability for all types of loading case. A possible way to overcome this difficulty is an energy criterion. Different forms of energy criteria have already been proposed and discussed for example by Ostergren [8], Ellyin et al.[9] or Halford [10]. These papers present different expressions of macroscopic deformation energy including or excluding its elastic, plastic or work-hardening part [11]

An interesting interpretation of the cyclic behaviour of the material is presented in Skelton [12]. These results [12] suggest that the cumulated dissipated energy to the cyclic response stabilization can be used as a crack initiation criterion in low cycle fatigue. Denoting by $\mathrm{N}_{\mathrm{S}}$ the number of cycles to stabilization, assumed to correspond to crack initiation, Skelton showed that the cumulated dissipated energy to stabilization: $\mathrm{Ns} \times \Delta \mathrm{W}_{\mathrm{s}}$ is relatively constant for a given material, between $1 \mathrm{~J} \cdot \mathrm{mm}^{-3}$ and $10 \mathrm{~J} \cdot \mathrm{mm}^{-3}$.

Our basic assumption is that the failure of the representative elementary volume corresponds to the failure criterion and in the case of a specimen, the failure of the representative elementary volume implies the complete failure. Using the ideas developed by Skelton, the present LCF and TMF tests on cast iron were analysed with a dissipated energy on the stabilized cycle.

The experimental versus predicted lifetime is presented in log-log plot in Figure 5.

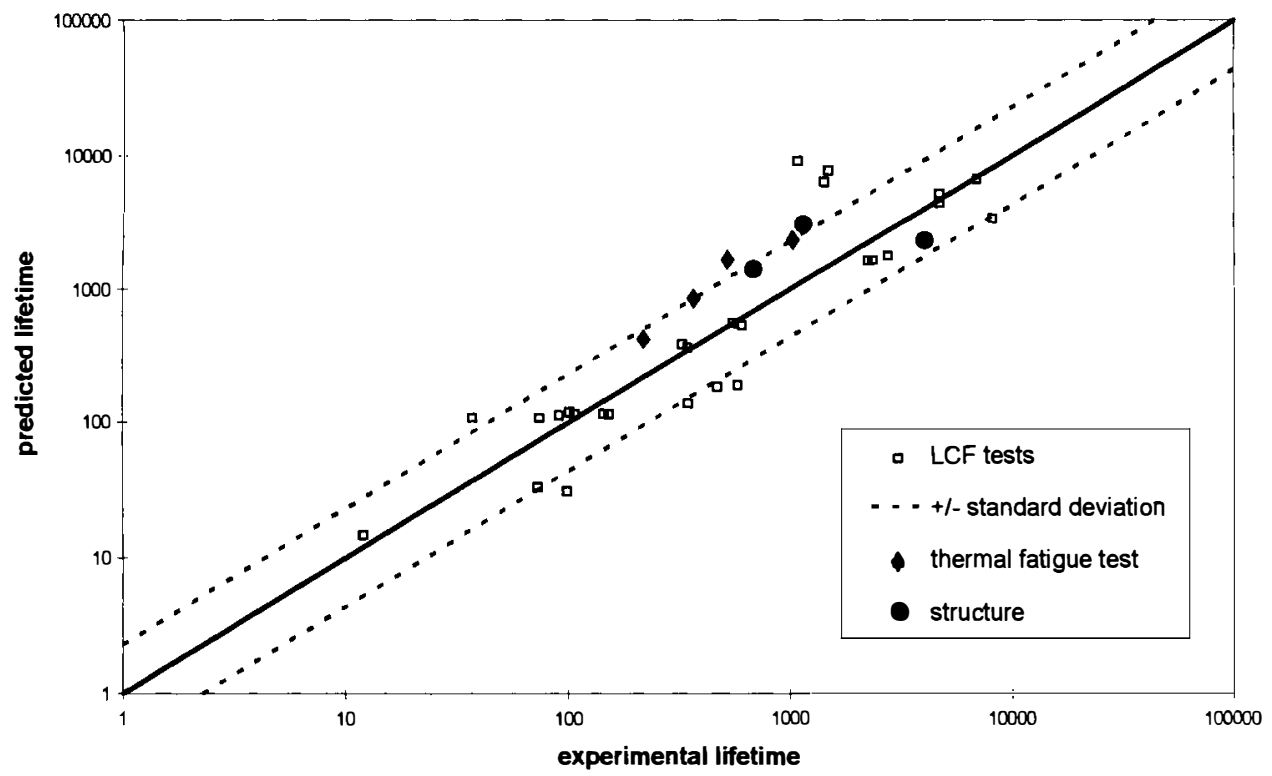

Figure 5 : comparison between estimated lifetime and predicted lifetime for LCF tests and thermal tests on specimens and anisothermal tests on real structures. 
The criterion itself has been established by linear regression using only LCF tests. For these tests the dissipated energy has been evaluated by numerical integration from the stress-strain experimental curves. The dissipated energy for the TMF tests on specimens or structures has been obtained by FEM computations using the energy of the stabilized cycle.

For LCF tests, the difference between experimental and predicted lifetime represents actually only the deviation for each point with the identified criterion. The standard deviation has been represented by the two dotted lines on the graphics. For TMF tests on specimens or structures, experimental lifetime is obtained with the tests and predicted lifetime is obtained using FEM computations. The computed dissipated energy distribution over the structure indicates precisely the experimental cracked region.

The cumulated energy to failure on components and specimens was showed to be of the same order of magnitude as reported by Skelton [12], i.e. between $1 \mathrm{~J} \cdot \mathrm{mm}^{-3}$ and $10 \mathrm{~J} \cdot \mathrm{mm}^{-3}$.

\section{CONCLUSION}

The aim of this paper was to investigate a possible low-cycle fatigue criterion and its applications to industrial structures subjected to thermomechanical loading.

It has been shown that a relatively simple elastoviscoplastic constitutive law can describe the mechanical behaviour of the structure in a large range of temperatures. The temperature dependance of the parameters permitted the emphasis on a plastic behaviour at low temperatures $\left(20^{\circ} \mathrm{C}-400^{\circ} \mathrm{C}\right)$ and a viscous behaviour at high temperatures $\left(400^{\circ} \mathrm{C}-800^{\circ} \mathrm{C}\right)$.

The dissipated energy per cycle, obtained directly from the computed stresses and strains demonstrated a robust fatigue criterion for the lifetime prediction of industrial structures. Moreover the total dissipated energy to failure has been found to be of the same order of magnitude as reported earlier by Skelton [12]. The applicability of an energy criteria to the lifetime prediction of structures subjected to complex low-cycle fatigue loadings has thus been proved.

However further efforts are necessary to improve the accuracy of life estimations of structures submitted to thermomechanical fatigue. A better quantitative understanding of the dissipation mechanisms and their relation to different types of failure will find a logical place in low-cycle fatigue lifetime predictions.

\section{REFERENCES}

1. R5, BNL report (1990) Berkeley Nuclear Laboratories, Nuclear Electric plc, Berkeley.

2. Dang Van, K. (1973) Sciences Technique Armement. Vol. 47, No 3.

3. Josefson, B.L., Stigh, U. and Hjelm, H.E. (1995) J. Engin. Mat. Tech. Vol. 117, pp 145-150.

4. Coffin, L. F. (1953) ASME, paper 53-A76, pp 931-950.

5. Manson, S. S. (1953) NACA, TN 2933.

6. Halford, G. R., and Manson, S. S. (1976) In : Thermal fatigue of materials and components, ASTM STP 612, pp 239-254.

7. Smith, K.N., Watson, P. and Topper, T. H. (1970) J. Mater. Vol. 5., No 4, pp 767-778.

8. Ostergren, W. J. (1976) J. Test. Eval. Vol. 4, No 5, pp 327-339.

9. Ellyin, F., and Golos, K. (1988) J. Eng. Mat. Tech. Vol. 110, pp 63-68.

10. Halford, G. R. (1966) J. Mater. Vol. 1, No. 1, pp 3-18

11. Lemaitre, J. and Chaboche, J.L. (1985) In : Mécanique des matériaux solides, Dunod editions, Paris

12. Skelton, R. P. (1991) Mat. Sc. Tech. Vol. 7, pp 427-439. 